\title{
The research on the construction of the spiritual civilization in the network
}

\author{
Xiaoming $\mathrm{Du}^{1, \mathrm{a}}$, Xinrong $\mathrm{TaO}^{2, \mathrm{~b}}$ and Kexin $\mathrm{Chen}^{1, \mathrm{c}}$ \\ ${ }^{1}$ Jiangsu University of Science and Technology, JiangSu 215600, China; \\ ${ }^{2}$ Zhangjiagang Admissions Office JiangSu 215600, China. \\ a260925671@qq.com; ;190571686@qq.com; ' $1224064189 @ q q . c o m$
}

Keywords: network spiritual civilization; construction; questionnaire.

\begin{abstract}
With the rapid development of information technology, the impact and challenge of the network culture on social morality, national culture and social ideology should not be underestimated. Construction of the corresponding network spiritual civilization has become an urgent task. In order to create a good morality, and effectively enhance the moral quality, this study uses the questionnaire to survey the users' views on civilization in the current network. Besides, the study analysis of challenges and reasons the current network culture security faces. What's more, we provide suggestions and countermeasures from the technical means, administrative means, legal means of proposed network spiritual civilization construction and management.
\end{abstract}

\section{Introduction}

$<$ Reports of Chinese online shopping market in 2015 >released by China Internet Network Information Center (CNNIC) on June 22 shows that by December 2015, the scale of China's Internet users has reached 6.88 billion and the size of mobile phone users has reached 620 million, besides, the Internet penetration rate was 50.3\%, 2.4 percentage points higher than that of the end of 2014[1].The scale of China's Internet users and the Internet penetration rate are shown in picture 1. Developments of network on social economy, politics, culture, ideology and morality and so on have a subtle influence. Network culture also has a huge impact on socialist spiritual civilization. On the positive side, network popularizes the educational, scientific and cultural knowledge, and enhances the artistic appreciation of the majority of users. But on the contrary, some negative information about the Internet is eroding people's spiritual world, so it is imperative to build the spiritual civilization of the network.

This paper is based on related theories and deeply analyzes the main content and important meanings of the construction of the spiritual civilization of the network, and finally discusses the new path of the construction of the spiritual civilization of the network.

\section{Related Theory}

(1)Network spiritual civilization

Network spiritual civilization refers to certain scientific and cultural quality along with the ideological and moral qualities of the users in the virtual community [2]. It's mainly about people's culture, ideological and moral, noble spirit and the value concept system in the various kinds of activities of the network community. It's a concrete manifestation of Socialist Spiritual Civilization.

(2)Construction of network spiritual civilization

Construction of network spiritual civilization is a construction of spiritual civilization in the virtual community; it mainly includes ideological and moral education, science and culture guidance. The network civilization needs a group of qualified users and a scientific and healthy network culture, so the group of constructing network spiritual civilization is large and the project is a very vast. 


\section{Research Process}

(1)Topic preparation

Members of the group divide the task. Each searches CNKI database and collects a large number of domestic and foreign literature or books about the spiritual civilization of the network for carding and refining, then they need to combine them with the actual life to form a new point of view.

(2)Questionnaire investigation

Develop a reasonable questionnaire based on the data collected from real life and release them through the issuance of network. The survey issued 100 questionnaires and recovered 95, 93 of them are valid questionnaires. The efficiency was 93\%. At the same time we visited many Internet users of different ages to understand their views and personal experience of network literature.

(3)Problem analysis

To analyze the statistics of questionnaires, we drew excel tables to show people's attitude towards the network civilization and the existing problems of the network community.

(4)Summing up the Countermeasures

We summarized consciousness of the construction of network spirit civilization, team, level and other issues to find the main problems and causes, and then put forward practical countermeasures to provide the basis for network management.

\section{The main problems of construction of network spiritual civilization}

From the 93 questionnaires, people think that the problem of the construction of spiritual civilization in the network is mainly concentrated in three aspects.

(1) People has the deviation of cognition about the construction of spiritual civilization in the network

From the survey, when it comes to whether to strengthen the network construction of spiritual civilization, $66.7 \%$ of the net friends said 'very meaningful'; $17.7 \%$ of the net friends thought 'of little significance'; 15.6 percent of they said 'does not matter'. It's visible that two-thirds of users believe that building network spiritual civilization is necessary; there are still $1 / 3$ of the net friends feel having nothing to do with them. This kind of metises are adhering to the 'natural development' theory, act freely on the network and they don't want to contribute any strength.

(2) The quality of the construction team of the spiritual civilization of the network is not high.

As to the problem of lack of management of the network construction, 30.2\% of people chose 'the lack of theoretical level', 35.3\% selected 'information technology level is not high', 33.3\% of people chose 'network regulatory responsibility is not strong' and 1.2 percent of people selected 'other'. Today, the phenomenon of network moral lose is serious, such as the lack of credibility of the network, inadequate network reason, rife network violence and so on. Regulatory is insufficient. Take the perspective of institutional rules for example, supervision and legislative departments on the network are multiple, legislative standards are not unified, so it's easy to give criminals loophole. From the point of view of regulators, some supervisors are lazy, they think 'more of less 'and are vulnerable to temptation. A little petty usually makes them relax the regulation so the result can only be more of a fish escaped through the Seine.

(3)Lack of technical support for the construction of the spiritual civilization in the network

Although through nearly ten years of network development, there emerges many new technologies; many of the people benefit a lot in the political, economic, cultural and other aspects. The ensuing computer viruses, hackers and loopholes in the system also emerge in an endless stream. As 'Maslow's hierarchy of needs' explains, people will only produce feelings, respect and self-realization after addressing demands of the physiological and safety needs. In order to consolidate and strengthen the construction of spiritual civilization, we must find solutions to the problem of network security. 


\section{Practical path of strengthening the spiritual civilization in the network}

From the data, three aspects result the lack of network civilization .They are misunderstandings of philosophy, lack of investment and ineffective regulation. So it is necessary to suit the remedy to the case, and put forward the corresponding solutions.

(1)Improve the quality of the construction team of the spiritual civilization in the network

One of the purposes of the construction of spiritual civilization in the network is to improve the core strength of cultural soft power and the overall development of people. For the backbone of the construction of spiritual civilization in the network, we must do the following.

Enhance the sense of social responsibility from the perspective of the interests of the country and society and give full play to the subjective initiative. At the same time, we need to establish the legal consciousness in the network environment and comply with social ethics, what's more, each one must self-discipline.

Establish correct network values and participate in the community topic actively. The spread of positive energy and prevention of the spread of rumors and other voices need everybody's effort. Everyone should not be tempted by the outside world.

(2)Increase investment of the construction of spiritual civilization

First, increase information infrastructure investment and use safe, reliable, harmless hardware and software to establish a solid infrastructure network, only in these way criminals cannot do anything.

The second is to increase capital investment. The 18th National Congress of the Communist Party of China emphasizes socialist spiritual civilization so the society has begun to pay attention to the construction of spiritual civilization [3]. Network spiritual civilization is also an essential part. Making good use of the network to enhance the ability of public opinion guiding can make more people come into contact with new ideas. The network media and staff training need a lot of money, but the effectiveness is proportional to the input.

The third is to increase staff input, network volunteers can be considered to join. Especially college students, they are new network generation and they contact new things, they know technical knowledge and have a strong social skills. Playing network volunteers will be able to bring with them social experience and they can also realize their own value.

(3)Improve the network supervision mechanism

From the perspective of government departments, the government's leading mechanism still needs to be improved. Decentralization and low inefficiency becomes components of public dissatisfaction. Nowadays government office platform has become more transparent, the government needs to improve their work processes urgently to serve the metises really. From the perspective of all trades and professions of the network, they need to improve the network industry self-regulation mechanism [4] and foster a sense of social responsibility. Only those enterprises who take society into account can go on the road to long-term.

(4)Perfect laws and regulations

Legislation stipulatess explicitly in real life and all rights are reserved, but law of the network is unsatisfactory. The establishment of a complete and independent of network system of laws and regulations is imminent. Relevant departments should speed up the legislative steps and individuals who violated standards of behavior must be investigated and held accountable. Once one imitator is under control, it can be effective against other imitators. At the same time, the laws and regulations of network should advance with the times. Only by constantly improving and perfecting the laws and regulations can we protect legitimate interests of the user?

\section{Conclusion}

Network is a problem of the whole society. Network spiritual civilization has a direct impact on social spiritual civilization. Using the network for the dissemination of positive energy becomes a new trend. The construction of network civilization should also keep up with the times the pace and insist on combining theory with practice, using feedback regulation and seeking truth from facts [5]. 
Network should actively play its positive effect and avoid negative effects as much as possible. Of course, this requires the joint efforts of all sectors of the community; I believe that we can build a better world network in the future.

\section{Acknowledgments}

This paper is the research findings of Zhangjiagang city social science applied research topic (Title: Analysis and countermeasure research on the problem of promoting the construction of the spiritual civilization of the network in Zhangjiagang in the new era; ID: 2016B42)

\section{References}

[1] China News Network: www.chinanews.com

[2] Peng Jianjun. Research on standards of the moral evaluation [J], Journal of University of South China (SOCIAL SCIENCE EDITION), 2001 (04)

[3] Wang Lihua. Reflections on the construction of the spiritual civilization of the Internet: Education exploration [J], 2003 (04)

[4] Mo Yan Wen. Construction of spiritual civilization in the network, Master's thesis of University of South China [D], 2013

[5] People's Daily Online: http://politics.people.com.cn/n/2015/0224/c1001-26591009.html 